ARTICLE

\title{
Direct insights into the role of epoxy groups on cobalt sites for acidic $\mathrm{H}_{2} \mathrm{O}_{2}$ production
}

Qingran Zhang (10 1, Xin Tan², Nicholas M. Bedford', Zhaojun Han 1,3,4, Lars Thomsen ${ }^{5}$, Sean Smith², Rose Amal ${ }^{1 凶} \&$ Xunyu Lu ${ }^{1 凶}$

Hydrogen peroxide produced by electrochemical oxygen reduction reaction provides a potentially cost effective and energy efficient alternative to the industrial anthraquinone process. In this study, we demonstrate that by modulating the oxygen functional groups near the atomically dispersed cobalt sites with proper electrochemical/chemical treatments, a highly active and selective oxygen reduction process for hydrogen peroxide production can be obtained in acidic electrolyte, showing a negligible amount of onset overpotential and nearly $100 \%$ selectivity within a wide range of applied potentials. Combined spectroscopic results reveal that the exceptionally enhanced performance of hydrogen peroxide generation originates from the presence of epoxy groups near the $\mathrm{Co}-\mathrm{N}_{4}$ centers, which has resulted in the modification of the electronic structure of the cobalt atoms. Computational modeling demonstrates these electronically modified cobalt atoms will enhance the hydrogen peroxide productivity during oxygen reduction reaction in acid, providing insights into the design of electroactive materials for effective peroxide production.

\footnotetext{
${ }^{1}$ Particles and Catalysis Research Group, School of Chemical Engineering, The University of New South Wales, Sydney, NSW 2052, Australia. ${ }^{2}$ Integrated Materials Design Laboratory, Department of Applied Mathematics, Research School of Physics and Engineering, The Australian National University, Canberra, ACT 2601, Australia. ${ }^{3}$ School of Mechanical and Manufacturing Engineering, The University of New South Wales, Sydney, NSW 2052, Australia. ${ }^{4}$ CSIRO Manufacturing, P.O. Box 218, 36 Bradfield Road, Lindfield, NSW 2070, Australia. ${ }^{5}$ Australian Synchrotron, Australian Nuclear Science and

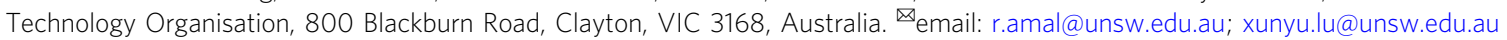


ydrogen peroxide $\left(\mathrm{H}_{2} \mathrm{O}_{2}\right)$ is an important chemical commodity that has been widely used as an environmentally benign oxidant and a potential energy carrier in various applications, including wastewater treatment ${ }^{1}$, disinfection, chemical synthesis ${ }^{2,3}$, paper/pulp bleaching, semiconductor cleaning ${ }^{4}$, and fuel cells ${ }^{5}$. The global demand of $\mathrm{H}_{2} \mathrm{O}_{2}$ is growing rapidly, reaching US $\$ 4.0$ billion in 2017 and is expected to further increase to around US $\$ 5.5$ billion by $2023^{6}$. Currently, over $95 \%$ of $\mathrm{H}_{2} \mathrm{O}_{2}$ is produced in a concentrated form using the anthraquinone process. This centralized production requires a huge infrastructure investment and high energy inputs, as well as poses safety concerns during the product distribution ${ }^{7}$. As a matter of fact, in many applications, only dilute $\mathrm{H}_{2} \mathrm{O}_{2}$ is required, indicating the concentrated peroxide agent needs to be diluted before usage. Moreover, the generation of organic byproducts and the hazard of handling the concentrated hydrogen peroxide make the anthraquinone method un-ecofriendly and uneconomic. Thus, it is highly desirable to develop green and cost-effective techniques for onsite $\mathrm{H}_{2} \mathrm{O}_{2}$ synthesis. Recently, the electrochemical reduction (ER) of oxygen via a selective two-electron transfer pathway has attracted extensive research interest as a promising alternative to the anthraquinone process. The oxygen reduction reaction (ORR) method will enable the decentralized production of $\mathrm{H}_{2} \mathrm{O}_{2}$ per demand under ambient reaction conditions without any hazardous byproducts ${ }^{8,9}$. Furthermore, if the ORR process is integrated with renewable electricity supplies (e.g., generation by photovoltaic cells or wind turbines), the $\mathrm{H}_{2} \mathrm{O}_{2}$ generated can be regarded as a renewable chemical $^{10}$.

More recently, there has been a surge of interest in developing metal-free carbon catalysts for the electro-synthesis of $\mathrm{H}_{2} \mathrm{O}_{2}$ via $\mathrm{O}_{2}$ reduction ${ }^{11,12}$. The electronic structure of these carbon materials can be easily tuned by heteroatom-doping ${ }^{13-15}$ or defectengineering ${ }^{16,17}$, thus endowing them high activity and selectivity towards $\mathrm{H}_{2} \mathrm{O}_{2}$ production in alkaline electrolytes. However, the production of $\mathrm{H}_{2} \mathrm{O}_{2}$ in alkaline media is somewhat constrained by the following limitations: (i) the $\mathrm{H}_{2} \mathrm{O}_{2}$ (or $\mathrm{HO}_{2}{ }^{-}$at a $\mathrm{pH}$ value above 11.6) tends to readily decompose at basic conditions ${ }^{18}$; (ii) chelating agents (e.g., ethylenediamine tetraacetic acid) are required to prevent the tramp-metal-ion-induced $\mathrm{H}_{2} \mathrm{O}_{2}$ decomposition, thus resulting in the increased operation $\operatorname{costs}^{19}$; (iii) devices (such as fuel cell) based on hydroxide-conducting polymeric electrolytes exhibit low membrane stability, poor water management and low hydrogen oxidation activity 20,21 . Therefore, it is more desirable to generate $\mathrm{H}_{2} \mathrm{O}_{2}$ in acids via ORR. Currently, the state-of-the-art electrocatalysts for $\mathrm{H}_{2} \mathrm{O}_{2}$ production in acid are still restricted to the precious-metal-based (e.g., $\mathrm{Pt}-\mathrm{Hg}$ and $\mathrm{Pd}-\mathrm{Hg}$ ) alloys or amalgams $\mathrm{s}^{22,23}$, while their high cost and scarcity have severely hindered their commercial viability. Mesoporous carbon with nitrogen dopants ${ }^{24}$ or a defective structure ${ }^{25}$ has emerged as a type of promising catalysts for $\mathrm{H}_{2} \mathrm{O}_{2}$ electrosynthesis in acids, owing to their high $\mathrm{H}_{2} \mathrm{O}_{2}$ selectivity and low cost. Nevertheless, large amounts of overpotential $(>400 \mathrm{mV})$ are normally associated with these materials to achieve high productivity and selectivity ${ }^{26,27}$, which has rendered the production process energy inefficient. Hence, the development of highly selective and active catalysts with low cost for electrolytic $\mathrm{H}_{2} \mathrm{O}_{2}$ production in acids is highly sought after.

In acids, the selective production of $\mathrm{H}_{2} \mathrm{O}_{2}$ via ORR requires the catalyst materials to adsorb the reaction intermediate, namely $\mathrm{OOH}^{*}$, with a suitable binding energy that could facilitate its single-electron reduction to $\mathrm{H}_{2} \mathrm{O}_{2}$, but suppress it from being further reduced or dissociated to $\mathrm{O}^{*}$ and $\mathrm{OH}^{*}$ that will eventually form $\mathrm{H}_{2} \mathrm{O}^{7,22}$. Thus far, porphyrins containing $3 \mathrm{~d}$ transition metals (such as $\mathrm{Fe}, \mathrm{Ni}$, and $\mathrm{Co}$ ) with an optimal binding energy toward $\mathrm{OOH}^{*}$ are found to be a type of effective and selective homogeneous catalysts for the electrolytic production of $\mathrm{H}_{2} \mathrm{O}_{2}$ in acids ${ }^{28}$, while the unstable $\mathrm{N}$ ligands under the harsh reaction conditions will inevitably result in rapid performance losses ${ }^{29}$. Therefore, it is of paramount importance to develop an effective method to stabilize these metal- $\mathrm{N}$ active species as well as maintain their high selectivity towards $\mathrm{H}_{2} \mathrm{O}_{2}$ production under the corrosive reaction environments, such as strong acids.

Forming single-atom catalysts (SACs) on a carbon substrate seems an appealing solution to stabilize the $\mathrm{N}$-coordinated transition-metal centers $\left(\right.$ metal $\left.^{-} \mathrm{N}_{x}\right)$. Apart from that, the conductive nature of a carbon substrate will also enable the maximal exposure of the active metal- $\mathrm{N}_{x}$ sites. Compared with other transition metals (like $\mathrm{Fe}$ ), Co-based composites exhibit less deleterious effects (like the active sites demetalation and Fenton reaction issue) that would eventually lead to the deactivation of the catalysts in acid ${ }^{30}$. Thus, in this work, a Co and $\mathrm{N}$ co-doped carbon nanotubes (CoN@CNTs) composite is prepared and employed as an electrocatalyst for ORR to produce $\mathrm{H}_{2} \mathrm{O}_{2}$ in acids. Moreover, by modifying the oxygen functionalities around the Co- $\mathrm{N}_{x}$ sites, significantly enhanced $\mathrm{H}_{2} \mathrm{O}_{2}$ catalytic performances can be obtained, showing both high activity (nearly zero overpotential) and selectivity ( 100\%), and exceeding nearly all the state-of-the-art catalysts and benchmarks reported in literature. Identification of specific oxygen functional groups in promoting the $\mathrm{H}_{2} \mathrm{O}_{2}$ production is carried out through a suite of spectroscopic measurements, revealing a synergy between epoxy $\mathrm{O}$ and $\mathrm{Co}-\mathrm{N}_{4}$ centers, as further confirmed by computational modeling. Finally, by employing the epoxy functionalized CoN@CNTs as the cathode catalyst, a customized $\mathrm{H}_{2} \mathrm{O}_{2}$ electrolyzer is fabricated that can easily produce over $0.1 \mathrm{wt} \%(1199 \mathrm{ppm}) \mathrm{H}_{2} \mathrm{O}_{2}$ within $30 \mathrm{~min}$, satisfying most of applications with an electro-Fenton process in water treatment $(>10 \mathrm{ppm})^{1}$.

\section{Results}

Synthesis and characterizations of CoN@CNTs catalysts. The CoN@CNTs composite was prepared by pyrolyzing the carbon and metal precursors in Ar, followed by an acid leaching to remove the accessible metallic debris (see details in the "Methods" section). To characterize the typical structural morphologies of CoN@CNTs, the scanning electron microscopy (SEM) and transition electron microscopy (TEM) were firstly employed. The SEM images (Fig. 1a) show that numerous carbon nanotubes were formed after pyrolysis. Besides that, a bamboo-like feature of the nanotube structure is revealed by the TEM images (Fig. $1 \mathrm{~b}$ and Supplementary Fig. 1), showing diameters ranging from 50 to $200 \mathrm{~nm}$. Further conducting the high-resolution TEM (HR-TEM) (Supplementary Fig. 1e-g) confirms the graphitic characteristic of the nanotube composite, showing an interlayer spacing of $\sim 0.35-0.36 \mathrm{~nm}$ on the CoN@CNTs, which could be ascribed to the (002) plane of graphitic carbon. Notably, the slightly larger $d-$ spacing of the (002) plane than that in a well-ordered structure of graphite $(0.33 \mathrm{~nm})$ indicates a somewhat disordered structure of the carbon basal plane in CoN@CNTs, which might be caused by the incorporation of $\mathrm{N}$ and $\mathrm{Co}^{31}$. The energy dispersive X-ray spectroscopy (EDS) elemental mapping of a selected area on the CoN@CNTs composite (Fig. 1c and Supplementary Fig. 2) exhibits uniform distributions of the $\mathrm{Co}, \mathrm{N}, \mathrm{O}$, and $\mathrm{C}$ elements across the tubular structure, demonstrating the successful incorporation of $\mathrm{Co}, \mathrm{N}$, and $\mathrm{O}$ into the carbon substrate. To identify the status of the Co species in CoN@CNTs, the high-angle annular dark field-scanning transmission electron microscopy (HAADF-STEM) measurement was conducted. As shown in Fig. 1d, the bright dots corresponding to Co atoms are homogenously dispersed throughout the CNTs. The statistical distribution of 50 pairs of two adjacent cobalt atoms shows that the 

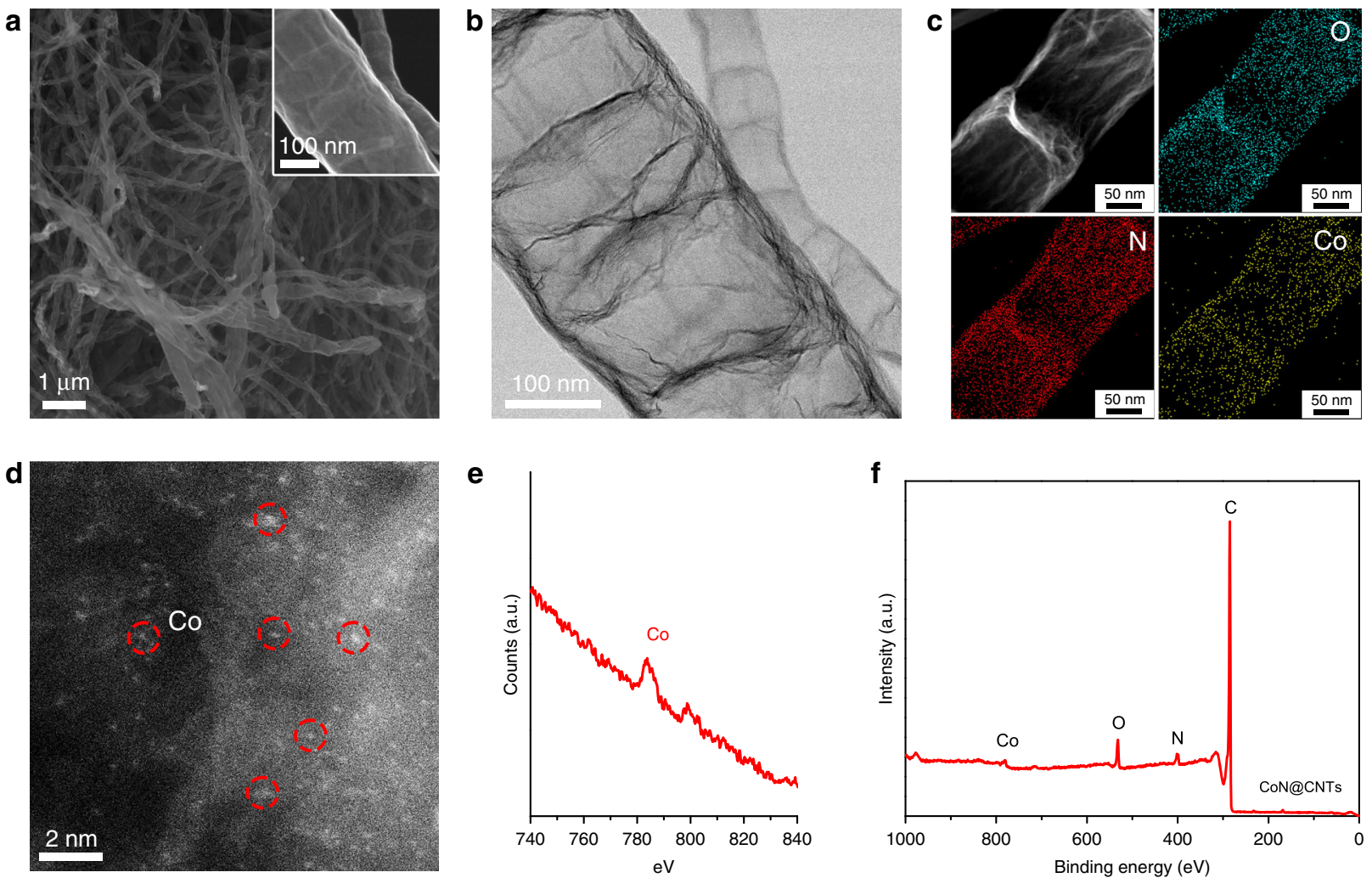

Fig. 1 Microstructural analysis of the CoN@CNTs catalyst. a SEM images of CoN@CNTs. Inset is the high-resolution SEM image of a selected area of CoN@CNTs. b TEM image of CoN@CNTs showing a bamboo-like structure of the carbon nanotubes. c HAADF-STEM image and corresponding EDS maps of CoN@CNTs for O, N, and Co. d HAADF-STEM image of the CoN@CNTs showing many Co atoms (circled in red) well-dispersed in the carbon layers. e EELS analysis of selected area in $\mathbf{d}$ showing the signals of Co. $\mathbf{f}$ XPS elemental survey of CoN@CNTs.

Co-Co distances are in the range from 0.2 to $0.8 \mathrm{~nm}$ and the majority $(\sim 80 \%)$ exhibits a distance $>0.4 \mathrm{~nm}$ (Supplementary Fig. 3), which suggests the dissociation of $\mathrm{OOH}^{*}$ intermediate or re-adsorption of hydrogen peroxide by the adjacent Co atoms (less than $4 \AA$ ) for the further reduction to water is less likely ${ }^{7}$. Electron energy loss spectroscopy (EELS) analysis (Fig. 1e) of an area within Fig. 1d further reveals the existence of isolated Co atoms in the carbon matrix. In addition, a very limited amount of Co nanoparticles encapsulated inside 5 to 7 layers of graphitic carbon shells are also observed at the closed end of several carbon nanotubes (Supplementary Fig. 4), while this $\mathrm{Co} / \mathrm{C}$ core-shell structure imposes negligible impacts on the electrolytic $\mathrm{H}_{2} \mathrm{O}_{2}$ production (see details in Supplementary Materials). The X-ray photon spectroscopy (XPS) elemental survey (Fig. 1f) also confirms the existence of $\mathrm{Co}, \mathrm{N}, \mathrm{O}$, and C on the CoN@CNTs. To further reveal the nature of the isolated Co atoms in CoN@CNTs, X-ray absorption near-edge structure (XANES) and extended X-ray absorption fine structure (EXAFS) measurements (Supplementary Fig. 5) were performed. The higher white line intensity and position compared with $\mathrm{Co}^{0}$ indicates the existence of positively charged Co with an oxidation state in CoN@CNTs. Furthermore, the slightly lower absorption edge position than that of cobalt(II) phthalocyanine (CoPc) suggests the valence state of atomic Co is situated between 0 and $2+$. The nearly absent appearance of a pre-edge feature (arisen from the forbidden 1s-to-3d transition) at $\sim 7709 \mathrm{eV}$ in the CoN@CNTs indicates a symmetric coordination environment of Co, e.g., $\mathrm{Co}-\mathrm{N}_{4}{ }^{32}$. Notably, the Fourier transformed (FT) Co K-edge EXAFS spectra exhibit the signal of light scattering nearest neighbors at $\sim 1.5 \AA$, corresponding to the $\mathrm{Co}-\mathrm{N} / \mathrm{C}$ scattering pair ${ }^{33,34}$ and further corroborating the existence of tetrahedrally coordinated Co (e.g., Co- $\left.\mathrm{N}_{4}\right)^{35,36}$ as revealed by fitting analysis (Supplementary Table 1). The weak signals originated from the Co-Co scattering path in a metallic feature might be ascribed to the rare appearance of Co nanoparticles.

Electrochemical measurements and study of active sites. The electrocatalytic performances and efficiency of CoN@CNTs for $\mathrm{H}_{2} \mathrm{O}_{2}$ production via ORR were examined in $\mathrm{O}_{2}$-saturated $0.1 \mathrm{M}$ $\mathrm{HClO}_{4}$ using a rotating ring-disk electrode (RRDE) setup. The $\mathrm{Pt}$ ring electrode was held at $1.2 \mathrm{~V}$ to quantify the amount of $\mathrm{H}_{2} \mathrm{O}_{2}$ produced on the disk electrode (see calculation details in the "Methods" section). Figure 2a shows the polarization curve obtained on CoN@CNTs, with the oxygen reduction current measured on the disk electrode (solid lines) and the $\mathrm{H}_{2} \mathrm{O}_{2}$ oxidation current measured on the Pt ring electrode (dashed lines). It is apparent that the CoN@CNTs composite exhibits a decent catalytic activity towards the electrolytic production of $\mathrm{H}_{2} \mathrm{O}_{2}$ in acid, showing obvious $\mathrm{H}_{2} \mathrm{O}_{2}$ oxidation currents at a potential range below $0.7 \mathrm{~V}$. Notably, the majority of electrons is consumed by a 2-electron pathway on the CoN@CNTs, showing a high $\mathrm{H}_{2} \mathrm{O}_{2}$ selectivity ( $\sim 80 \%$ from 0.5 to $0.7 \mathrm{~V}$, Supplementary Fig. 6 ), as determined by RRDE measurements. In contrast, the FeN@CNTs and NiN@CNTs composites prepared via a similar method with an analogous nanotube structure (Supplementary Fig. 7) both exhibit a low $\mathrm{H}_{2} \mathrm{O}_{2}$ productivity and selectivity $(<40 \%)$ within the same potential range, demonstrating the intrinsic active nature of $\mathrm{Co}-\mathrm{N}_{4}$ species in selectively reducing $\mathrm{O}_{2}$ to $\mathrm{H}_{2} \mathrm{O}_{2}{ }^{37}$. Moreover, the Tafel slope of CoN@CNTs is much lower than that of FeN@CNTs and NiN@CNTs (Supplementary Fig. 8), indicating faster ORR kinetics on CoN@CNTs and further suggesting the superior role of $\mathrm{Co}-\mathrm{N}_{4}$ species in reducing oxygen. 

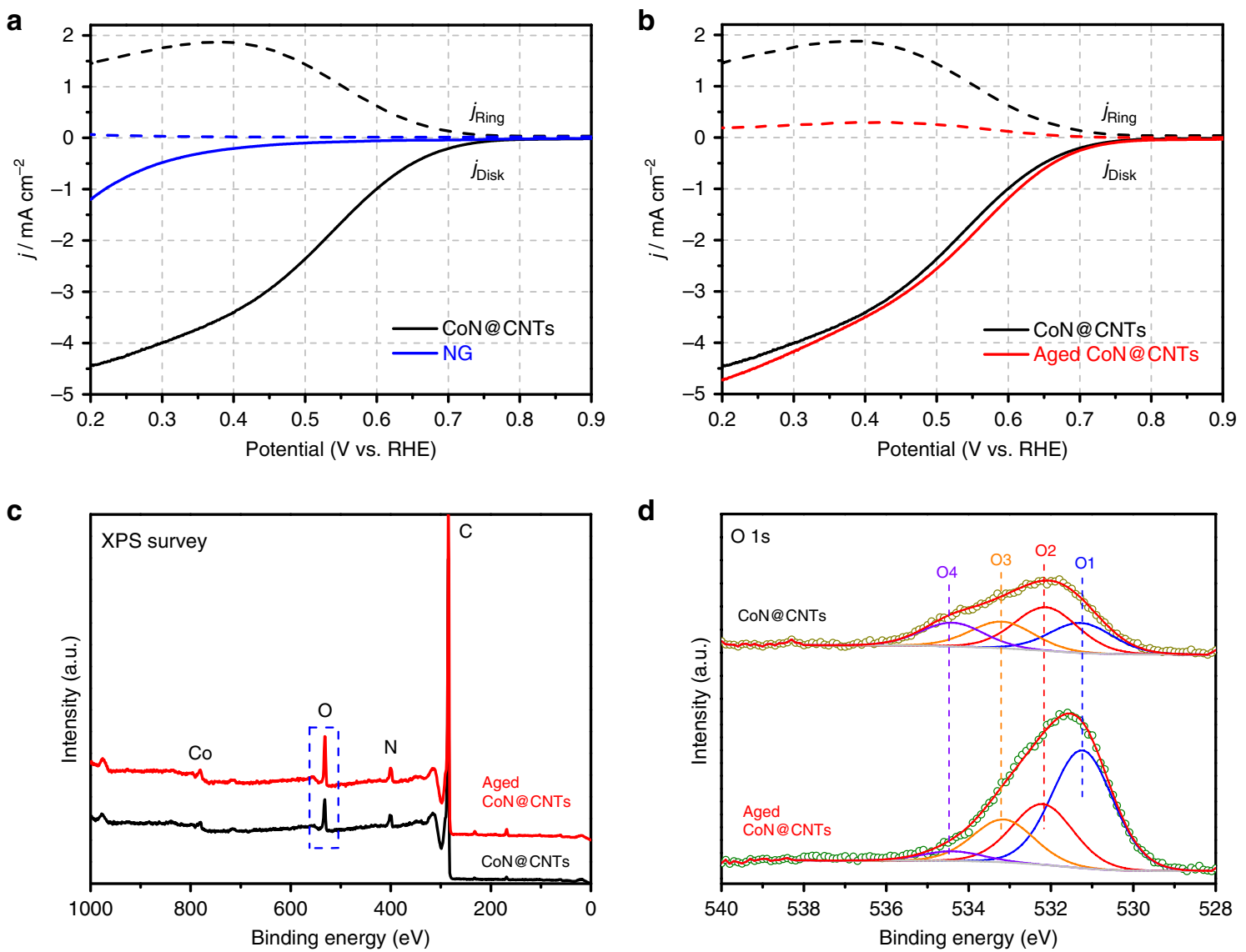

Fig. 2 Oxygen reduction performance of CoN@CNTs. a RRDE voltammograms of CoN@CNTs and NG at 1600 rpm in an $\mathrm{O}_{2}$-saturated $0.1 \mathrm{M} \mathrm{HClO} 4$ electrolyte with disc current and ring current. b RRDE voltammograms of fresh and aged CoN@CNTs at 1600 rpm in an $\mathrm{O}_{2}$-saturated $0.1 \mathrm{M} \mathrm{HCIO} 4$ electrolyte with disc current and ring current. All potentials are recorded without iR correction. c XPS elemental survey of CoN@CNTs and aged CoN@CNTs.dXPS O 1s spectra of CoN@CNTs and aged CoN@CNTs.

Furthermore, in the absence of Co species, nitrogen-doped graphene (NG) with a similar amount of $\mathrm{N}$ dopants (Supplementary Table 2) to the CoN@CNTs composite exhibits negligible $\mathrm{H}_{2} \mathrm{O}_{2}$ production within the whole potential range tested herein (Fig. 2a, blue lines), confirming the prerequisite role of $\mathrm{Co}-\mathrm{N}_{4}$ in enabling the efficient $\mathrm{H}_{2} \mathrm{O}_{2}$ generation via ORR. The same conclusion can also be obtained with the poisoning experiment, where a significantly receded $j_{\text {disk }}$ was detected after the $\mathrm{Co}-\mathrm{N}_{4}$ centers were poisoned by thiocyanate ions $\left(\mathrm{SCN}^{-}\right)$(details can be found in Supplementary Fig. 9). Similarly, single Co atom embedded mesoporous carbon (M-CoNC, Supplementary Fig. 10) prepared via a different method also exhibits a $\mathrm{H}_{2} \mathrm{O}_{2}$-favored ORR process within the same range of potentials, demonstrating the 2electron-transfer pathway is dominating the $\mathrm{O}_{2}$ reduction process on the $\mathrm{Co}-\mathrm{N}_{4}$ sites in acid and precluding the possible effect from the $\mathrm{Co} / \mathrm{C}$ core-shell structure. Notably, during a three-hour $\mathrm{H}_{2} \mathrm{O}_{2}$ production session (Supplementary Fig. 11), the selectivity is maintained at $\sim 78 \%$ with negligible drop, showing a decent stability on the CoN@CNTs under the static operation conditions.

However, despite its high catalytic performance, after a longterm ( 30 days) exposure to air, the selectivity of the CoN@CNTs composite towards $\mathrm{H}_{2} \mathrm{O}_{2}$ production falls dramatically. Figure $2 \mathrm{~b}$ compares the RRDE curves obtained with freshly prepared CoN@CNTs and CoN@CNTs that has been exposed to air for one month (named as aged CoN@CNTs). It can be seen from Fig. 2b that $j_{\text {ring }}$ on the aged CoN@CNTs drops significantly meanwhile the $j_{\text {disk }}$ remains almost unchanged (compared with CoN@CNTs), leading to the $\mathrm{H}_{2} \mathrm{O}_{2}$ selectivity $<30 \%$ over the whole potential range. This phenomenon indicates the occurrence of some unwanted oxidation process on the CoN@CNTs composite during the air exposure that has jeopardized its $\mathrm{H}_{2} \mathrm{O}_{2}$ productivity. This assumption is further confirmed by the electrochemical measurements of the CoN@CNTs composite that has been stored in vacuum for the same duration, exhibiting almost identical ORR activity and $\mathrm{H}_{2} \mathrm{O}_{2}$ selectivity (Supplementary Fig. 12). XPS was utilized to reveal the chemical changes between the CoN@CNTs and aged CoN@CNTs composites. As displayed in Fig. 2c, Supplementary Fig. 13 and Supplementary Table 2, the only noticeable change between these two samples is the increment of $\mathrm{O}$ concentration, which rises from 3.50 at\% in CoN@CNTs to 5.17 at \% in aged CoN@CNTs. More details are provided by the highresolution XPS O 1s spectra (Fig. 2d) of the two composites, which involve four oxygen components ${ }^{38,39}$ : (i) ketonic oxygen $(\mathrm{C}=\mathrm{O}$, $\mathrm{O} 1,531.2 \pm 0.2 \mathrm{eV})$, (ii) oxygen atoms in epoxy $(\mathrm{C}-\mathrm{O}-\mathrm{C})$ or hydroxyl groups and carbonyl oxygen in ester groups (O2, 532.3 \pm $0.2 \mathrm{eV})$, (iii) the epoxy oxygen in ester groups $(\mathrm{O} 3,533.3 \pm 0.2 \mathrm{eV})$, and (iv) oxygen atoms in carboxyl groups $(\mathrm{O} 4,534.2 \pm 0.2 \mathrm{eV})$. Among all the four $\mathrm{O}$ functionalities detected within the composite, only the ketonic groups (O1) have gone through a noticeable increment, of which the concentration has increased from merely 0.84 at $\%$ in the fresh sample to 2.64 at $\%$ in the aged sample (Supplementary Table 3). This observation suggests that the ketonic groups might be responsible for the receded $\mathrm{H}_{2} \mathrm{O}_{2}$ productivity on the aged CoN@CNTs. Therefore, further study is warranted to find an effective method to mitigate the influence of this negative effect.

Electrochemical treatment (ET) is selected here as an approach to in situ re-construct the surface oxygen functionalities on the 

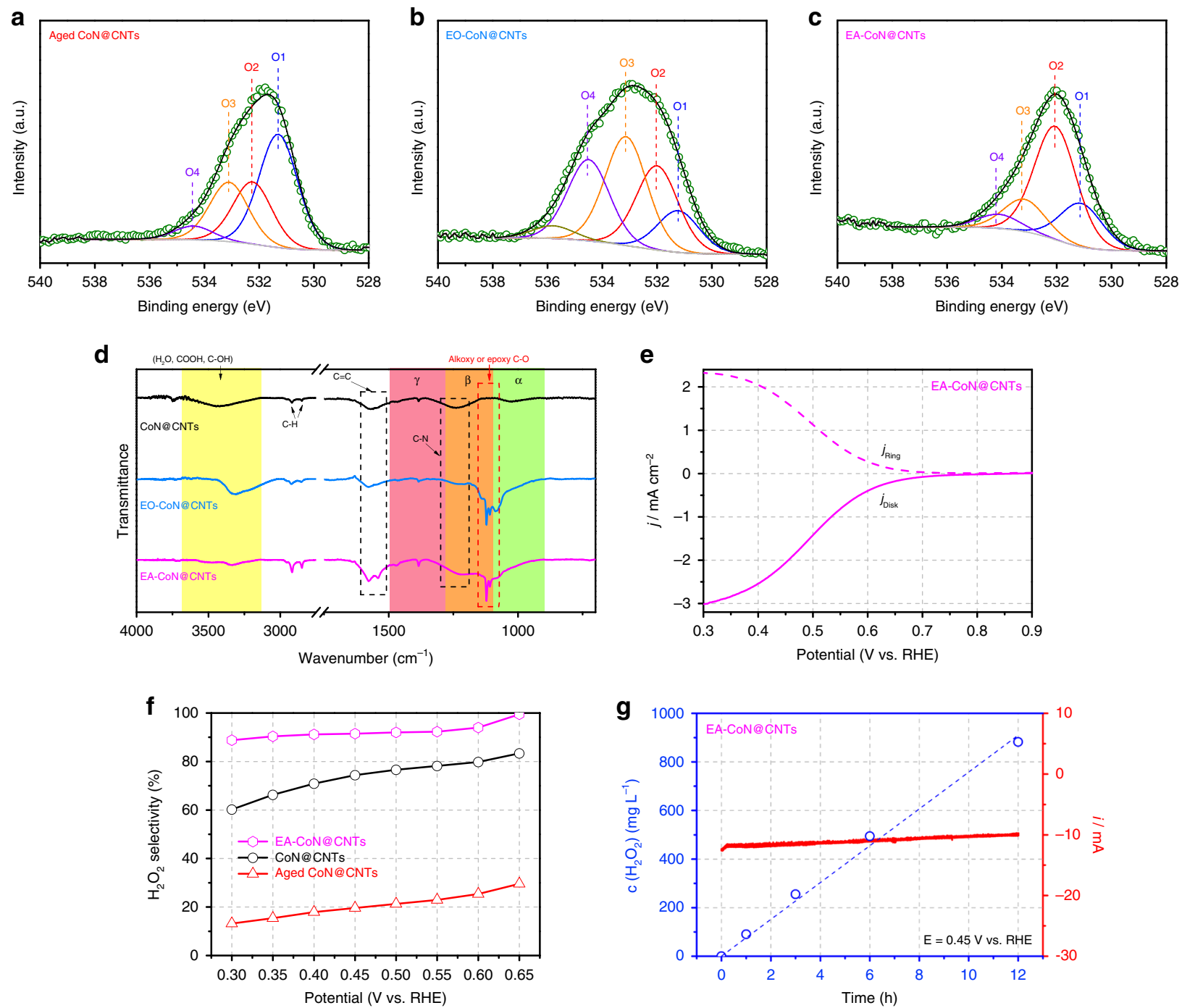

Fig. 3 Electrochemical activation (EA) of CoN@CNTs. XPS O 1s spectra of a aged CoN@CNTs, b EO-CoN@CNTs and c EA-CoN@CNTs. d Backgroundcorrected FTIR spectra of CoN@CNTs before and afterETs. e RRDE voltammograms of CoN@CNTs after EA (including EO and then ER) at 1600 rpm in an $\mathrm{O}_{2}$-saturated $0.1 \mathrm{M} \mathrm{HClO}_{4}$ electrolyte with disc current and ring current. f Calculated $\mathrm{H}_{2} \mathrm{O}_{2}$ selectivity on CoN@CNTs, aged CoN@CNTs and EACoN@CNTs based on the RRDE measurements. $\mathbf{g ~} \mathrm{H}_{2} \mathrm{O}_{2}$ production amount (determined via the potassium permanganate titration) as a function of time on the EA-CoN@CNTs. Current (red curve) and concentration (blue $\mathrm{O}$ ) behavior with time for the electrochemical $\mathrm{H}_{2} \mathrm{O}_{2}$ production is shown.

carbon-based materials. Nevertheless, simply doing ER is hard to remove those oxygen functional groups (like ketonic $\mathrm{O}$ ) that are thermodynamically more stable than the carboxyl groups ${ }^{40}$. As expected, the aged CoN@CNTs before and after ER treatment exhibits almost identical chemical properties (Supplementary Fig. 14) as well as $\mathrm{H}_{2} \mathrm{O}_{2}$ productivity (Supplementary Fig. 15), suggesting the ineffectiveness of ER in reconstructing the oxygen functionalities on CoN@CNTs. Compared with the ER process, the electrochemical oxidation (EO) treatment is more effective in rebuilding the surface oxygen functional groups on carbon-based materials $^{41}$. Thus, herein, a two-step electrochemical process combing both EO and ER is adopted to treat the aged CoN@CNTs to modify the O functionalities. Firstly, the aged CoN@CNTs was electrochemically oxidized in the $0.1 \mathrm{M} \mathrm{HClO}_{4}$ solution (EO-CoN@CNTs) by an anodic linear sweep voltammetric scan (details can be referred to Supplementary Fig. 16). Based on the post-reaction XPS measurements (Fig. 3b), the EO treatment endows the aged CoN@CNTs composite a higher O content (12.66 at\%, Supplementary Table 2) owing to the highly positive potential applied that caused carbon oxidation. Specifically, the EO-CoN@CNTs exhibits a higher ratio of O2 and O4, while that of ketonic $\mathrm{O}(\mathrm{O} 1)$ decreases, indicating the electrochemical generation of epoxy and carboxyl groups on the CoN@CNTs and a possible conversion of $\mathrm{C}=\mathrm{O}$ into other $\mathrm{O}$ species during this treatment. Then, the EO-CoN@CNTs was subjected to an ER treatment to afford the electrochemically activated CoN@CNTs (EA-CoN@CNTs, Supplementary Fig. 17). From the XPS O 1s spectrum (Fig. 3c) of the EA-CoN@CNTs, it is interesting to note that, after ER process, the ratios of $\mathrm{O} 3$ and O4 both drop dramatically (from 33.2 and $24.7 \%$ to 15.9 and $6.9 \%$ respectively) while that of the $\mathrm{O} 2$ becomes dominant (55.8\%) compared with those of EO-CoN@CNTs (Supplementary Fig. 18). The significantly reduced amount of $\mathrm{O} 3$ and $\mathrm{O} 4$ can be correlated to the reduction of some $\mathrm{O}$ functional groups (like ester and carboxyl) under a cathodic potential, coinciding with the observations in the previous work ${ }^{40}$. Epoxy groups are thermodynamically more stable than ester/carboxyl groups ${ }^{38,40}$, and they are hard to be removed by ER. Therefore, compared with the aged CoN@CNTs, the exclusively increased $\mathrm{O} 2$ species in the EA-CoN@CNTs can be attributed to the apparent emergence of epoxy groups on the catalysts. Fourier-transform infrared spectroscopy (FTIR) measurements (Fig. 3d) further 
confirm the appearance of these epoxy functionalities on the EA-CoN@CNTs, showing a strong and broad absorption band (alkoxy or epoxy C-O) at a region from 1000 to $1200 \mathrm{~cm}^{-1}$ as reported in recent studies 42,43 .

To understand the impact of $\mathrm{O}$ functionalities on the $\mathrm{Co}-\mathrm{N}_{4}$ centers, $\mathrm{N}$ 1s and Co 2p XPS spectra were analyzed on the electrochemically treated samples. The $\mathrm{N} 1 \mathrm{~s}$ spectrum shows that pyridonic $\mathrm{N}$ has increased substantially after ETs (details can be referred to Supplementary Fig. 19) while the concentration of pyridinic $\mathrm{N}$ has decreased, suggesting a possible conversion between these two $\mathrm{N}$ species. Thus, it is plausible to postulate that during the ETs, the epoxy groups produced will preferably bond to $\mathrm{C}$ atoms that are adjacent to the pyridinic $\mathrm{N}$ (coordinated with Co atoms), and consequently transform the pyridinic $\mathrm{N}$ to pyridonic $\mathrm{N}^{44}$. This postulation is further supported by the Co $2 \mathrm{p}_{3 / 2}$ XPS spectrum presented in Supplementary Fig. 20, where the Co-N peak in EA-CoN@CNTs shifts positively to a higher binding energy side $(\sim 780.7 \mathrm{eV})$ than that in the pristine CoN@CNTs $(\sim 780.4 \mathrm{eV})^{45}$, demonstrating the electro-generated $\mathrm{O}$ groups (e.g. epoxy) could be in the vicinity of $\mathrm{Co}-\mathrm{N}_{\mathrm{x}}$ centers and pose an electron-withdrawing effect that has affected the electronic structure of the Co atoms. In contrast, the ETs show no obvious influence on the valence state of Co species, reflected by the similar spin-energy separation values of samples before and after ETs (Supplementary Fig. 20). Moreover, no leaching of Co in the electrolyte was detected by the inductively coupled plasma mass spectroscopy (ICP-MS) measurement during the ETs, indicating the chemically stable property of the Co sites.

To testify the effectiveness of the ETs, electrolytic $\mathrm{H}_{2} \mathrm{O}_{2}$ production over the EA-CoN@CNTs was also evaluated in $\mathrm{O}_{2}$-sat. $0.1 \mathrm{M} \mathrm{HClO}_{4}$ solution. Surprisingly, EA-CoN@CNTs exhibits a superior $\mathrm{H}_{2} \mathrm{O}_{2}$ productivity that is even higher than the freshly prepared CoN@CNTs. Specifically, the onset potentials of EA-CoN@CNTs at the ring and disk coincide at $\sim 0.7 \mathrm{~V}$ (Fig. 3e), which is the thermodynamic onset potential of the genuine 2-electron pathway of ORR in acid for $\mathrm{H}_{2} \mathrm{O}_{2}$ production ${ }^{22}$. As the overpotential increases, most of the $j_{\text {disk }}$ recorded on EA-CoN@CNTs can be accounted for the production of $\mathrm{H}_{2} \mathrm{O}_{2}$. The selectivity of $\mathrm{H}_{2} \mathrm{O}_{2}$ production is well above $90 \%$ within a region between 0.3 and $0.6 \mathrm{~V}$ (Fig. 3f) based on the RRDE measurement, indicating a nearly complete 2-electron ORR process on the EA-CoN@CNTs. Also, at a potential of $0.3 \mathrm{~V}$, the $j$ on the disk $\left(0.125 \mathrm{~cm}^{2}\right)$ achieves $3 \mathrm{~mA} \mathrm{~cm}^{-2}$, which is close to the theoretical mass transport limit for the 2-electron reduction of oxygen $^{22}$. To investigate the Faradaic efficiency (FE) and stability of EA-CoN@CNTs during bulk electrolysis, the electrocatalytic $\mathrm{H}_{2} \mathrm{O}_{2}$ production and accumulation through ORR was carried out in a $\mathrm{H}$-cell setup separated by a Nafion membrane with continuous $\mathrm{O}_{2}$ bubbling. The FE was verified for the purpose of a more intuitive demonstration employing permanganate titration (average of three repetitions) ${ }^{22}$ within a range of potentials from 0.45 to $0.65 \mathrm{~V}$. Of note, the titration results (Supplementary Fig. 21) exhibit a FE as high as 95\%, which coincides with the RRDE results. The long-term stability performed via a chronoamperometric measurement at $0.45 \mathrm{~V}$ for $12 \mathrm{~h}$ (Fig. $3 \mathrm{~g}$ ) yields a current of $\sim 10 \mathrm{~mA}$, during which the concentration of accumulated $\mathrm{H}_{2} \mathrm{O}_{2}$ also increased continuously. The slight drop in current was attributed to the possible attachment of some species (like cations or $\mathrm{H}_{2} \mathrm{O}_{2}$ ) on the surface of electrode, and this can be recovered after changing the electrolyte and rinsing the electrode (Supplementary Fig. 22). From the electrochemical results shown above, it is evident that the synergistic effect between $\mathrm{Co}-\mathrm{N}_{4}$ centers and their adjacent $\mathrm{C}-\mathrm{O}-\mathrm{C}$ groups plays an advocating role in reducing oxygen exclusively to $\mathrm{H}_{2} \mathrm{O}_{2}$, which makes the EA-CoN@CNTs among the most effective catalyst for electrolytic $\mathrm{H}_{2} \mathrm{O}_{2}$ production in acids (Supplementary Table 4).
C-O-C groups on carbon can also be introduced through chemical approaches and $\mathrm{H}_{2} \mathrm{O}_{2}$ treatment (HT) was previously found to be an effective method ${ }^{46}$. Hence, to further understand the critical role of epoxy functionalized $\mathrm{Co}-\mathrm{N}_{4}$ centers in promoting the 2-electron ORR for $\mathrm{H}_{2} \mathrm{O}_{2}$ production, aged CoN@CNTs sample was chemically treated in $0.1 \mathrm{M} \mathrm{HClO}_{4}$ solution containing $5 \mathrm{wt} \% \mathrm{H}_{2} \mathrm{O}_{2}$ at $70{ }^{\circ} \mathrm{C}$ for $2 \mathrm{~h}$. A dominant presence of epoxy groups is detected by both XPS (Supplementary Fig. 23a) and FTIR (Supplementary Fig. 23b) on the $\mathrm{H}_{2} \mathrm{O}_{2}$-treated CoN@CNTs (HT-CoN@CNTs), accompanied by a significantly reduced intensity of the ketonic group, suggesting the effectiveness of this treatment. As expected, HT-CoN@CNTs exhibits a much higher $\mathrm{H}_{2} \mathrm{O}_{2}$ selectivity (Supplementary Fig. 24a) as well as productivity (Supplementary Fig. 24b) than the aged CoN@CNTs, echoing the findings from the ETs. Thus, to further enhance the $\mathrm{H}_{2} \mathrm{O}_{2}$ productivity of the CoN@CNTs composite, both HT and electrochemical activation (EA) methods were applied together (see details in the "Methods" section) on the aged CoN@CNTs sample to obtain the HE-CoN@CNTs. As expected, a high content of O (12.3 at\%) and the highest ratio of epoxy groups (71.3\%) among all samples prepared were obtained (Supplementary Fig. 25a and Table 3), accompanied by an obviously increased ratio of pyridonic N (Supplementary Fig. 25b). The HE-CoN@CNTs exhibits, to the best of our knowledge, a record-breaking catalytic performance towards $\mathrm{H}_{2} \mathrm{O}_{2}$ production in acid. Shown in Fig. $4 \mathrm{a}$, b, with the onset potential at $0.7 \mathrm{~V}$, the HE-CoN@CNTs composite is capable of maintaining a nearly $100 \%$ selectivity of $\mathrm{H}_{2} \mathrm{O}_{2}$ production within a wide potential range from 0.3 to $0.6 \mathrm{~V}$ (>95\%), exceeding the catalytic performances of those benchmarks and state-of-the-art catalysts, including precious metals, their alloys and recently reported carbon-based materials (Fig. 4c, Supplementary Table 4), in terms of both overpotential and selectivity. In contrast, the NG exhibits a much lower $\mathrm{H}_{2} \mathrm{O}_{2}$ current within the same potential range even after the $\mathrm{H}_{2} \mathrm{O}_{2}$ treatment and ETs (Supplementary Fig. 26), further advocating the importance of synergies between $\mathrm{CoN}_{4}$ active sites and nearby $\mathrm{C}-\mathrm{O}-\mathrm{C}$ groups. Post-reaction characterizations (XPS and FTIR, Supplementary Figs. 27 and 28) show negligible changes on the HE-CoN@CNTs after a 12-h reaction session, evidencing the fact that not only the Co species, but also the epoxy groups are stable during ORR. In addition, the catalytic activity and $\mathrm{H}_{2} \mathrm{O}_{2}$ selectivity is kept almost unchanged on the HE-CoN@CNTs sample even after long-term aging period in air. This is due to the chemically stable property of these epoxy functionalities on catalysts that eventually benefit a well retained $\mathrm{H}_{2} \mathrm{O}_{2}$ selectivity after aging, as revealed by FTIR and XPS O 1s spectra (Supplementary Fig. 29). Moreover, within a gas diffusion electrode (GDE, Supplementary Fig. 30) setup, the $\mathrm{H}_{2} \mathrm{O}_{2}$ concentration could be easily accumulated to $1199 \mathrm{ppm}$ within 30 min at $0 \mathrm{~V}$, which is sufficient for direct usage in industries like water disinfection and bleaching ${ }^{1}$. At a more moderate potential (0.3 V, Supplementary Fig. 31), $5525 \mathrm{ppm}$ of $\mathrm{H}_{2} \mathrm{O}_{2}$ is produced within $12 \mathrm{~h}$, giving the energy-efficient feature of this process as less overpotentials are required. Notably, even when the reaction is conducted using air bubbling (Fig. $4 \mathrm{~b}$ ), the $\mathrm{H}_{2} \mathrm{O}_{2}$ selectivity is still maintained at $>80 \%$ within the whole voltage range, demonstrating its potential to be applied in practical applications.

To further corroborate the correlation between the emerged epoxy oxygen and the enhanced $\mathrm{H}_{2} \mathrm{O}_{2}$ selectivity, near-edge X-ray absorption fine structure (NEXAFS) measurements were performed on the post-treated CoN@CNTs samples. As shown in Supplementary Fig. 32a, high-resolution oxygen K-edge NEXAFS results of EO-CoN@CNTs,EA-CoN@CNTs, HT-CoN@CNTs and HE-CoN@CNTs all exhibit obvious features at $~ 533.4$ and $534.8 \mathrm{eV}$, corresponding to transitions of $\mathrm{O} 1 \mathrm{~s}$ core level electrons to final states of $\pi^{*}$ symmetry localized at C-O bond of epoxy groups ${ }^{14,47-49}$. The intense peak arisen at around $539 \mathrm{eV}$ in the 
a

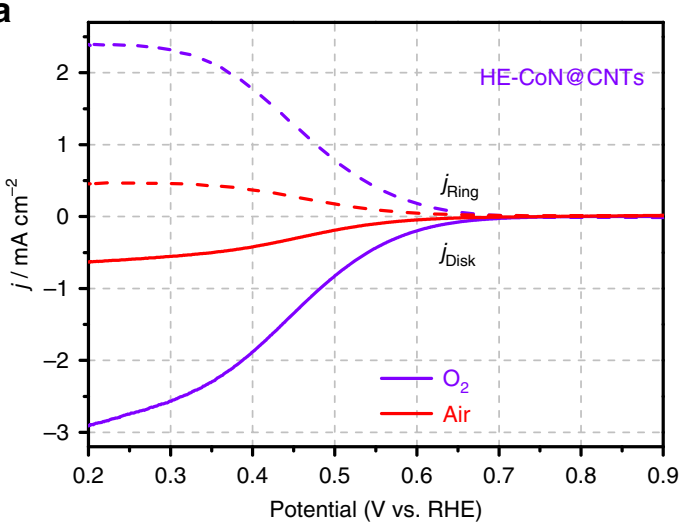

C

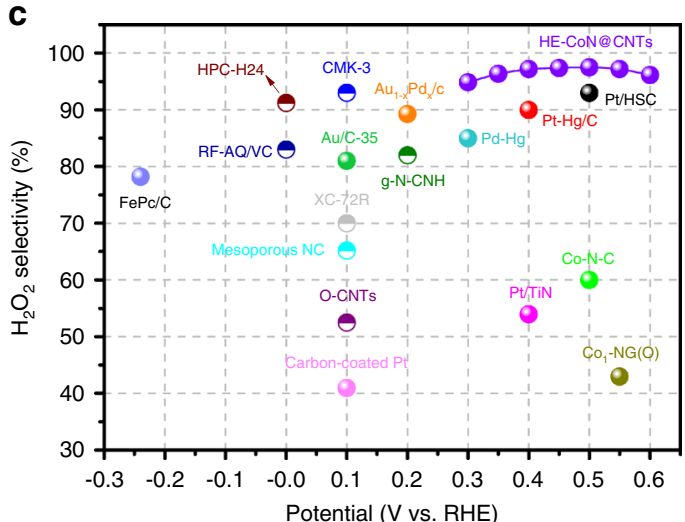

e

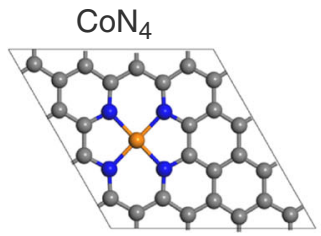

b

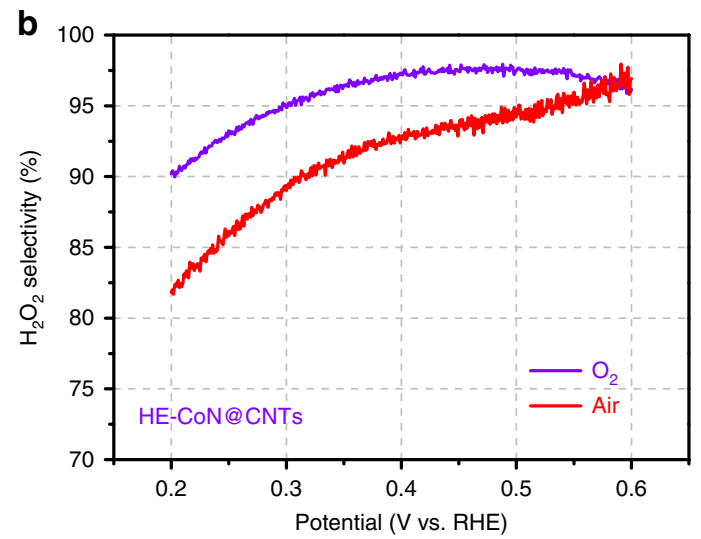

d

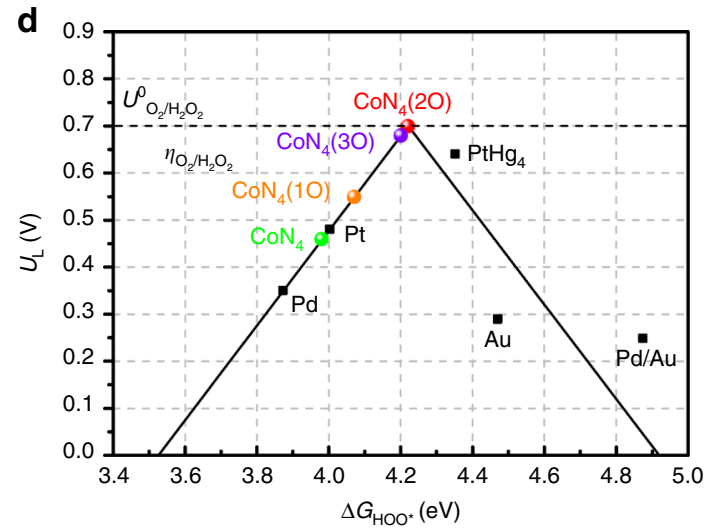

$\mathrm{CoN}_{4}(2 \mathrm{O})$
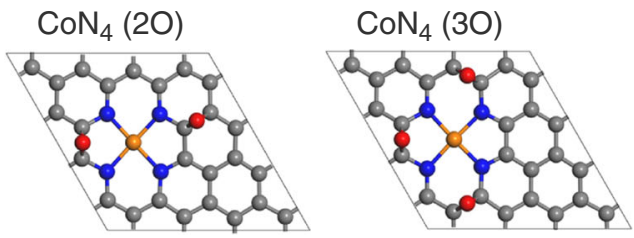

Fig. 4 ORR activities of HE-CoN@CNTs and DFT results of different types of epoxy-modified Co-N $\mathbf{N}_{\mathbf{4}}$ sites. a RRDE measurements of HE-CoN@CNTs for ORR in $0.1 \mathrm{M} \mathrm{HClO}_{4}$ solution purged with $\mathrm{O}_{2}$ and air. $\mathbf{b}$ Calculated $\mathrm{H}_{2} \mathrm{O}_{2}$ selectivity on $\mathrm{HE}-\mathrm{CoN} @ C N T s$ in $\mathrm{O}_{2}$ - and air-saturated $0.1 \mathrm{M} \mathrm{HClO}$ based on the RRDE measurements. $\mathbf{c ~} \mathrm{H}_{2} \mathrm{O}_{2}$ selectivity on $\mathrm{HE}-\mathrm{CoN} @ C N T s$ and other recently reported catalysts (Supplementary Table 4) in acidic media. d Calculated Sabatier volcano plot for the 2-electron ORR to $\mathrm{H}_{2} \mathrm{O}_{2}$ for bare $\mathrm{CoN}_{4}$ moiety and $\mathrm{CoN}_{4}$ moieties with different epoxy oxygen coverages obtained from DFT simulations. The $\mathrm{U}_{\mathrm{L}}$ is plotted as a function of $\Delta \mathrm{G}_{\mathrm{HOO}}$. The black solid lines represent the theoretical Sabatier volcano ${ }^{22}$. The black squares are the data adapted from ref. ${ }^{22}$. e The optimized geometry structures of bare $\mathrm{CoN}_{4}$ moiety and $\mathrm{CoN}_{4}$ moieties with different epoxy oxygen coverages, which were chosen to calculate the ORR activities in this work. Here, $\mathrm{CoN}_{4}$ indicates bare $\mathrm{CoN}_{4}$ moiety. $\mathrm{CoN}_{4}(10), \mathrm{CoN}_{4}(2 \mathrm{O})$, and CoN 4 (3O) indicate $\mathrm{CoN} 4$ moieties with 1, 2 or 3 epoxy oxygen, respectively. The gray, blue, orange and red balls represent $\mathrm{C}, \mathrm{N}, \mathrm{Co}$ and $\mathrm{O}$ atoms, respectively.

spectra curves of those samples after chemical and/or ETs can be ascribed to the transitions to $\sigma^{*}$ states of $\mathrm{C}-\mathrm{O}$ bonding from ring $\mathrm{C}-\mathrm{O}-\mathrm{C}$ functionalities ${ }^{48}$, further confirming the emergence of epoxy O. Notably, the bisphenol A diglycidyl ether (BADGE) composite gives rise to obvious $\pi^{*}$ and $\sigma^{*}$ resonances at around 534.2 and $539.0 \mathrm{eV}$ (Supplementary Fig. 32a), respectively, signifying the emergence of $\mathrm{C}-\mathrm{O}-\mathrm{C}$ groups in our samples. The split of antibonding $\pi^{*}$ symmetry of $\mathrm{C}-\mathrm{O}$ bond in the posttreatment CoN@CNTs is probably ascribed to the high coverages of epoxy functionalities on the surface of carbon basal plane ${ }^{47}$. In addition, Co L-edge spectra (Supplementary Fig. 32b) show significant fine-structure at $\mathrm{L}_{3}$ peak due to the multiplet structure from electron-electron interaction, which depends greatly on the local coordination symmetry of Co sites. As expected, the $\mathrm{CoN} @ \mathrm{CNTs}$ sample exhibits the signatures of $\mathrm{CoN}_{x}$ moieties very close to $\mathrm{Co}-\mathrm{N}-\mathrm{C}$ catalysts in previous reports ${ }^{30}$, suggesting a tetrahedrally coordinated $\left(\mathrm{T}_{\mathrm{d}}\right)$ symmetry of Co atoms in our catalysts, which is consistent with the XANES Co K-edge results. The spectra of EA-CoN@CNTs, HE-CoN@CNTs and EO-CoN@CNTs show promiment fine-structure features at 778.5 and $779.0 \mathrm{eV}$, which are similar to the oxygen-induced distored $\mathrm{CoN}_{4}$ functionalities as reported previously ${ }^{50}$, causing a "octahedral-like" symmetry on the Co sites by nearby $\mathrm{O}$ atoms. Notably, the increases in overall intensity for those epoxy-modified samples (EA-CoN@CNTs, HE-CoN@CNTs and EO-CoN@CNTs) are acribed to electrons transferring away from the Co atoms, strongly implicating that nearby $\mathrm{O}$ atoms from epoxy groups are modifying the electronic structure of the Co sites (e.g., electron-withdrawing effect) and thus their ability to selectively produce hydrogen peroxide. NEXAFS Co L-edge spectrum from bulk $\mathrm{Co}_{3} \mathrm{O}_{4}$ reference is shifted to higher energy as expected for increase in oxidation state, suggesting that bulk oxidiation is not found in our materials during the electrochemical and chemical treatments. 
Theoretical simulations. The above experimental results demonstrated that the electrochemical/chemical treatments of CoN@CNT generate abundant amounts of epoxy groups, which may tailor the electronic structure of the $\mathrm{CoN}_{4}$ moieties and significantly improve their 2-electron-pathway ORR activity for the $\mathrm{H}_{2} \mathrm{O}_{2}$ production. To elucidate the mechanism within this enhancement effect, density functional theory (DFT) calculations were performed. Extensive details regarding the calculations are available in the Supplementary Materials. Here we considered epoxy oxygen on $\mathrm{CoN}_{4}$ catalysts with different coverage and locations (Supplementary Figs. 33 and 34), and chose the possible structures (Fig. 4e) with low epoxy oxygen formation energy $\left(E_{\mathrm{ep}-\mathrm{O}}^{F}\right)$ to calculate the ORR activity. Supplementary Fig. 35 shows the free-energy diagrams for the 2-electron ORR to $\mathrm{H}_{2} \mathrm{O}_{2}$ at the equilibrium potential $\left(U_{\mathrm{O}_{2} / \mathrm{H}_{2} \mathrm{O}_{2}}^{0}=0.70 \mathrm{~V}\right)$, and the theoretically calculated ORR volcano plot for the 2-electron pathways is given in Fig. 4d. It can be seen from Fig. $4 \mathrm{~d}$ and Supplementary Fig. 35 that the introduction of epoxy groups close to $\mathrm{CoN}_{4}$ moiety dramatically weaken the binding strength of $\mathrm{HOO}^{*}$ on the Co atoms. Especially for the structures of $\mathrm{CoN}_{4}$ moiety with 2 or 3 epoxy oxygens, the computed values of $\Delta G_{\mathrm{HOO}^{*}}$ for $\mathrm{CoN}_{4}(2 \mathrm{O})$ and $\mathrm{CoN}_{4}(3 \mathrm{O})$ are 4.22 and $4.20 \mathrm{eV}$, respectively, which are located at the peak of the 2-electron volcano with $U_{\mathrm{L}}=0.70$ and $0.68 \mathrm{~V}$, respectively. These results suggest that the $\mathrm{CoN}_{4}$ moiety with nearby epoxy groups exhibits their superior activity and selectivity of the 2-electron ORR to $\mathrm{H}_{2} \mathrm{O}_{2}$ with the overpotentials less than $0.02 \mathrm{~V}$, which are comparable or even lower than that of the state-of-the-art $\mathrm{PtHg}_{4}$ for the 2-electron ORR to $\mathrm{H}_{2} \mathrm{O}_{2}$ in acidic conditions $(\eta<0.10 \mathrm{~V})^{22}$. In contrast, the epoxy oxygen formed at the carbon atoms far from the Co- $\mathrm{N}_{4}$ centers (Supplementary Fig. 33) exhibits negligible effect in optimizing the binding energy of $\mathrm{HOO}^{*}$ intermediate at Co sites, indicating the importance of synergies between $\mathrm{CoN}_{4}$ moieties and those nearby epoxy groups. The Bader analysis reveals that the decrease of $\Delta G_{\mathrm{HOO}}$ for $\mathrm{CoN}_{4}$ moiety with epoxy groups is due to the electrowithdrawing groups ${ }^{51}$, i.e., epoxy oxygen, deplete the electrons on $\mathrm{Co}$ atom of $\mathrm{CoN}_{4}$ moiety. For example, the electrons on Co are $+0.92 e$ and $+0.97 e$ for $\mathrm{CoN}_{4}$ and $\mathrm{CoN}_{4}(3 \mathrm{O})$, respectively, based on the Bader analysis, echoing with the electron-transferring effect between $\mathrm{Co}$ and nearby $\mathrm{O}$ atoms observed in NEXAFS measurements. Furthermore, the climbing image nudged elastic band (CI-NEB) method is also performed to calculate the chemical dissociation barrier of $\mathrm{HOO}^{*}$ on the active site, elucidating the origin of the $\mathrm{H}_{2} \mathrm{O}_{2}$ selectivity on the epoxy-modified $\mathrm{CoN}_{4}$ sites. As expected, the dissociation energy of $\mathrm{HOO}^{*}$ on the $\mathrm{CoN}_{4}$ sites is high $(1.4 \mathrm{eV})$, and that can be further increased after epoxy-modification (Supplementary Fig. 36), suggesting the possible $\mathrm{O}-\mathrm{O}$ bond session could be effectively suppressed on the epoxy-modified $\mathrm{CoN}_{4}$ moieties that in turn benefit an improved $\mathrm{H}_{2} \mathrm{O}_{2}$ selectivity. This is further supported by the previous hypothesis that the chemical cleavage of $\mathrm{O}-\mathrm{O}$ bond by the adjacent carbon atoms near the $\mathrm{M}-\mathrm{N}$ sites could be sterically blocked by their surrounding oxygen groups ${ }^{46}$.

\section{Discussion}

While the above results unequivocally confirm the synergies between epoxy oxygen and $\mathrm{CoN}_{4}$ species in promoting the $\mathrm{H}_{2} \mathrm{O}_{2}$ productivity, the possible effect of limited amount of hydroxyl groups in influencing the ORR selectivity cannot be fully excluded. Thus, the role of hydroxyl oxygen on the $\mathrm{H}_{2} \mathrm{O}_{2}$ productivity is also evaluated as it may cast a similar influence on the $\mathrm{CoN}_{4}$ centers. As expected, simulation results reveal a similar electronwithdrawing effect of $-\mathrm{OH}$ functionalities on the $\mathrm{CoN}_{4}$ species (Supplementary Fig. 37), which might facilitate the $\mathrm{H}_{2} \mathrm{O}_{2}$ formation. Nevertheless, the binding energy of $\mathrm{OOH}^{*}$ on the hydroxyl-modified $\mathrm{CoN}_{4}$ centers is still not as optimal as that on the epoxy-modified active sites (Supplementary Fig. 35). Moreover, in this study, the possible origin of $\mathrm{H}_{2} \mathrm{O}_{2}$ selectivity from the synergies between $-\mathrm{OH}$ species and $\mathrm{CoN}_{4}$ sites are further precluded by a set of experiments. Hot-alkaline treatment is regarded as effective in introducing - $\mathrm{OH}$ groups as well as converting $\mathrm{C}-\mathrm{O}-\mathrm{C}$ functionalities into other species ${ }^{52}$. Thus, the aged CoN@CNTs sample was heated in concentrated $\mathrm{KOH}$ solution (see details in "Methods"), generating an ample amount of hydroxyl oxygen but no obvious $\mathrm{C}-\mathrm{O}-\mathrm{C}$ groups were observed (Supplementary Fig. 38). Notably, no enhancement of $\mathrm{H}_{2} \mathrm{O}_{2}$ selectivity was identified on the hot-alkaline-treated sample, suggesting a limited effect of $-\mathrm{OH}$ groups in affecting the $\mathrm{H}_{2} \mathrm{O}_{2}$ formation. Therefore, it can be concluded that the significantly enhanced $\mathrm{H}_{2} \mathrm{O}_{2}$ selectivity on the $\mathrm{CoN}_{4}$ active sites is mainly due to the emergence of epoxy oxygen rather than hydroxyl groups near the Co atoms. Previous reports suggest that oxidation of carbon can significantly influence the $\mathrm{H}_{2} \mathrm{O}_{2}$ performance on $\mathrm{M}-\mathrm{N}-\mathrm{C}(\mathrm{M}=\mathrm{Co}, \mathrm{Fe}, \mathrm{Mn})$ catalysts $^{46,53}$. However, no direct correlations between specific oxygen functionalities and $\mathrm{H}_{2} \mathrm{O}_{2}$ selectivity has been established, causing a debate on the real origin of $\mathrm{H}_{2} \mathrm{O}_{2}$ selectivity as the influence of diverse $\mathrm{O}$ groups cannot be universal. Herein, the enhancement effect of epoxy groups on $\mathrm{H}_{2} \mathrm{O}_{2}$ selectivity is answered systematically, providing guidelines in not only design of efficient catalysts for peroxide production but also stabilizing the performance of SACs in acidic fuel cells. Further, all these experiments and simulations strongly prove the effectiveness of our electrochemical/chemical approach in tuning the selectivity of $\mathrm{O}_{2}$ reduction through surface reconstruction on carbon-based materials, which could be readily adopted for other selectivity-critical electrochemical reactions, like $\mathrm{N}_{2}$ or $\mathrm{CO}_{2}$ reduction.

In summary, the DFT calculation provides an explanation for the synergistic effects observed experimentally over the EACoN@CNTs and HE-CoN@CNTs composites with significantly improved activity as well as selectivity towards $\mathrm{H}_{2} \mathrm{O}_{2}$ production in acidic electrolytes. The electronic structure of Co- $\mathrm{N}_{4}$ centers has been tuned by the presence of epoxy groups that are adjacent to them, resulting in the close-to-ideal binding energy that allows the ORR to proceed via a nearly complete two-electron transfer pathway to produce $\mathrm{H}_{2} \mathrm{O}_{2}$. Both the EA-CoN@CNTs and HE-CoN@CNTs composites exhibit record-breaking $\mathrm{H}_{2} \mathrm{O}_{2}$ productivity, outperforming nearly all the catalyst materials reported previously. Further optimizations of the catalyst materials as well as devices obtained in this study, including improved long-term stability (up to several thousand hours), faster mass transport in the electrolyzer and accelerated $\mathrm{H}_{2} \mathrm{O}_{2}$ production rate in air ${ }^{54,55}$, will be carried out to warrant their future practical applications.

\section{Methods}

Materials. All reaction reagents and chemicals were obtained and used in their asreceived form without any further purification. Dicyandiamide, $\mathrm{Co}\left(\mathrm{NO}_{3}\right)_{2} \cdot 6 \mathrm{H}_{2} \mathrm{O}$, $\mathrm{Ni}\left(\mathrm{NO}_{3}\right)_{2} \cdot 6 \mathrm{H}_{2} \mathrm{O}, \mathrm{Fe}\left(\mathrm{NO}_{3}\right)_{3} \cdot 9 \mathrm{H}_{2} \mathrm{O}$, Nafion solution (5 wt\%) and cobalt(II) phthalocyanine $(\mathrm{CoPc})$ were obtained from Sigma-Aldrich. Deionized water was obtained through the water purification system (Milli-Q water) in the lab.

Synthesis and surface treatments of CoN@CNTs. Typically, to prepare the CoN@CNTs catalyst, $3.5 \mathrm{mmol} \mathrm{Co}\left(\mathrm{NO}_{3}\right)_{2} \cdot 6 \mathrm{H}_{2} \mathrm{O}, 35 \mathrm{mmol}$ dicyandiamide and 2 $\mathrm{mL}$ ethanol were mixed in an agate mortar, followed by continuous grinding until the mixture forms a uniform pink paste. The as-obtained mixture was placed into a crucible boat and heated to $800^{\circ} \mathrm{C}$ with a ramping rate of $3^{\circ} \mathrm{C} \mathrm{min}-1$ for $3.5 \mathrm{~h}$ under Ar atmosphere. The impurities and undesirable nanoparticles outside the carbon nanotubes were removed through an acid leaching process in $0.5 \mathrm{M} \mathrm{H}_{2} \mathrm{SO}_{4}$ at $90{ }^{\circ} \mathrm{C}$ for $4 \mathrm{~h}$, followed by repeatedly filtered and washed process in deionized water. The FeN@CNTs and NiN@CNTs were prepared using the similar pyrolysis process by changing the type of metal nitrate in the precursors. The effect of carbonization time on $\mathrm{H}_{2} \mathrm{O}_{2}$ productivity was investigated in detail, and we found that CoN@CNTs pyrolyzed at $800{ }^{\circ} \mathrm{C}$ for $3.5 \mathrm{~h}$ yields the highest ORR activity towards $\mathrm{H}_{2} \mathrm{O}_{2}$ production (Supplementary Fig. 39). The M-CoNC composite was 
synthesized via a modified method as reported previously ${ }^{56}$. The polymerized OPD (Phenylenediamine, Sigma Aldrich, 99.99\%) in presence of hydrochloric acid and APS (Ammonium persulfate, Sigma Aldrich, 99.99\%) was mixed with Co $\left(\mathrm{NO}_{3}\right)_{2} \cdot 6 \mathrm{H}_{2} \mathrm{O}$ and then pyrolyzed at $900^{\circ} \mathrm{C}$ under $\mathrm{Ar}$ for $2 \mathrm{~h}$ to form M-CoNC. NG was directly purchased from Sigma Aldrich (99.99\%). To obtain the HTCoN@CNTs, the CoN@CNTs powder was dispersed and heated in $50 \mathrm{~mL} 0.1 \mathrm{M}$ $\mathrm{HClO}_{4}$ solution containing $5 \mathrm{wt} \% \mathrm{H}_{2} \mathrm{O}_{2}$ under $70^{\circ} \mathrm{C}$ for $2 \mathrm{~h}$. The EA-CoN@CNTs was obtained by oxidizing the CoN@CNTs electrochemically through conducting an anodic linear sweep voltammetric scan from 1.2 to $2.4 \mathrm{~V}$ vs. RHE, followed by an ER process via a cathodic linear sweep voltammetric scan from 0.6 to $-0.6 \mathrm{~V}$ vs. RHE. To prepare the HE-CoN@CNTs, the CoN@CNTs sample was treated through a combined HT and EA process. Hot-alkaline treatment was conducted by heating the aged CoN@CNTs sample in 6 $\mathrm{M} \mathrm{KOH}$ solution with an autoclave reactor under $180^{\circ} \mathrm{C}$ for $12 \mathrm{~h}$.

Physicochemical characterizations. Transmission electron microscopy (TEM) was carried out on a Phillips/CM 200 microscope operated at an accelerating voltage of $200 \mathrm{kV}$. SEM was conducted on a JEOL $7001 \mathrm{~F}$ operated at $5 \mathrm{kV}$. FTIR measurements were conducted on a PerkinElmer FTIR Spectrometer. X-ray photoelectron spectroscopy (XPS) measurements were carried out on a Thermo ESCALAB250Xi X-ray photoelectron spectrometer using $\mathrm{Cu} \mathrm{Ka} \mathrm{X-rays} \mathrm{as} \mathrm{the} \mathrm{excitation} \mathrm{source} \mathrm{with} \mathrm{a}$ voltage of $12.5 \mathrm{kV}$ and power of $250 \mathrm{~W}$. High-angle annular dark field-scanning transmission electron microscopy (HAADF-STEM) and energy dispersive X-ray (EDX) mapping were obtained on a spherical aberration corrected transmission electron microscope (FEI Titan G2 80-200) which was operated at $200 \mathrm{kV}$. ICP-MS was carried out using a PerkinElmer quadrapole Nexion instrument. Co K-edge Xray absorption spectroscopy (XAS) measurements were performed at the 10-ID-B beamline of the Advanced Photon Source (APS), Argonne National Laboratory (ANL). Data were collected using a fluorescence geometry and scanned from $200 \mathrm{eV}$ below the Co K-edge $(7709 \mathrm{eV})$ to $\sim 1000 \mathrm{eV}$ past the edge. Data reduction and subsequent modeling efforts were performed using the Demeter software package ${ }^{57}$. Modeling results used a Co- $\left(\mathrm{N}_{3} \mathrm{C}_{2}\right)_{2}$ cluster to modeling $\mathrm{Co}-\mathrm{N}$ and $\mathrm{Co}-\mathrm{C}$ backscattering paths ${ }^{58}$. An $\mathrm{S}_{0}{ }^{2}$ value of 0.776 was used for all models and obtained from modeling a reference Co foil. O K-edge and Co L-edge NEXAFS measurements were performed at the SXR beamline of the Australian Synchrotron. Powders were pressed onto Ir foil and mounted onto metallic sample holders for measurements under partial electron yield (PEY) mode. O K-edge measurements were performed from $520 \mathrm{eV}$ to $580 \mathrm{eV}$ while Co L-edge measurements were performed from 770 to $810 \mathrm{eV}$ and internally calibrated using $\mathrm{MnO}$ and Co foil reference samples respectively. All data processing, energy calibrations, and normalization was performed using the program QANT.

DFT calculations. All of the spin-polarized DFT calculations were performed using the VASP program ${ }^{59-61}$, which uses a plane-wave basis set and a projector augmented wave method (PAW) for the treatment of core electrons ${ }^{59}$. The Perdew, Burke, and Ernzerhof exchange-correlation functional within a generalized gradient approximation (GGA-PBE) ${ }^{62}$ was used in our calculations, and the van der Waals (vdW) correction proposed by Grimme (DFT-D3) was employed due to its good description of long-range vdW interactions $s^{63}$. For the expansion of wavefunctions over the planewave basis set, a converged cutoff was set to $400 \mathrm{eV}$. Dipole correction was considered in all cases. Extensive details were given in from Supplementary Figs. 33-37.

Electrochemical measurements. The electrochemical tests were all performed in $0.1 \mathrm{M} \mathrm{HClO}_{4}$ aqueous solution within a three-electrode system at room temperature on a computer-controlled potentiostat (CH Instrument, $\mathrm{CHI} 760 \mathrm{E})$. The oxygen reduction activity and selectivity were investigated by polarization curves and rotating ring-disk electrode (RRDE) measurements in oxygen-saturated electrolyte with a scan rate of $5 \mathrm{mV} \mathrm{s}^{-1}$. A glassy carbon electrode loaded with catalyst was used as the working electrode. A graphite rod and a saturated calomel electrode were used as counter and reference electrode respectively. To prepare the working electrode loaded with the catalyst, typically, $5 \mathrm{mg}$ as-prepared catalyst and $25 \mu \mathrm{L}$ Nafion solution (Sigma Aldrich, 5 wt \%) were dispersed in $1 \mathrm{~mL}$ ethanol aqueous solution (50\%) to form a homogeneous ink with the help of a sonication process for $30 \mathrm{~min}$. Then, $6.5 \mu \mathrm{L}$ of the ink was dropcasted onto the surface of a polished glassy carbon electrode and dried under room temperature in atmosphere. The final loading of the catalysts on working electrode was $0.25 \mathrm{mg} \mathrm{cm}^{-2}$. Commercially available $\mathrm{Pt} / \mathrm{C}$ catalyst (20 wt\% of $\mathrm{Pt}$, Sigma-Aldrich) was employed as the benchmark for $4 \mathrm{e}^{-}$ORR process to testify the electrochemical testing conditions in acid (Supplementary Fig. 40). All of the obtained potentials were calibrated to a reversible hydrogen electrode (RHE, $E_{\mathrm{RHE}}=E_{\mathrm{SCE}}+0.2415+0.059 \times \mathrm{pH}$ ). No correction of the system resistance was employed. The Tafel slope was calculated using the Tafel equation: $\eta=\mathrm{b} \log \left(j / j_{\mathrm{o}}\right)\left(\eta, \mathrm{b}, j\right.$, and $j_{\mathrm{o}}$ represent the overpotential, Tafel slope, current density and exchange current density respectively).

$\mathrm{H}_{2} \mathrm{O}_{2}$ selectivity of the catalysts was calculated from the current of both disc and ring electrodes using the following equation:

$$
\mathrm{H}_{2} \mathrm{O}_{2}(\%)=200 \times \mathrm{I}_{\mathrm{r}} / \mathrm{N} /\left(\mathrm{I}_{\mathrm{d}}+\mathrm{I}_{\mathrm{r}} / \mathrm{N}\right)
$$

where $I_{d}$ is disk current, $I_{r}$ is ring current, and $N$ is current collection efficiency of the Pt ring. $\mathrm{N}$ was determined to be 0.32 in our system after calibration using the reversible $\left[\mathrm{Fe}(\mathrm{CN})_{6}\right]^{4-/ 3-}$ redox couple ( +0.36 vs. SHE). A potential of $1.2 \mathrm{~V}$ vs. RHE was applied on the Pt ring of the working electrode at a speed of 1600 r.p.m. during the entire testing process.

FE and electrocatalytic production of $\mathrm{H}_{2} \mathrm{O}_{2}$ were measured in a twocompartment cell with Nafion membrane as separator. Both the cathode compartment $(75 \mathrm{~mL})$ and anode compartment were filled with $0.1 \mathrm{M} \mathrm{HClO}_{4}$ aqueous solution. Oxygen was continuously purged into the cathode (working) compartment under vigorous stirring. A graphite rod and a saturated calomel electrode were used as counter and reference electrode respectively. A hydrophobic carbon fiber paper (CFP) loaded with as-prepared CoN@CNTs catalyst $\left(0.5 \mathrm{mg} \mathrm{cm}^{-2}\right)$ was used as the working electrode.

To quantify the amount of $\mathrm{H}_{2} \mathrm{O}_{2}$ produced, we carried out an independent test not based on electrochemical methods: permanganate titration. Typically, samples with a volume of $1 \mathrm{~mL}$ collected at certain time intervals were diluted into $10 \mathrm{~mL}$ and titrated with $0.005 \mathrm{M} \mathrm{KMnO}_{4}$ aqueous solution. The concentration of $\mathrm{H}_{2} \mathrm{O}_{2}$ produced was calculated according to the following equation:

$$
\mathrm{C}_{\mathrm{H} 2 \mathrm{O} 2}=5 \mathrm{C}_{\mathrm{KMnO} 4} \times \mathrm{V}_{\mathrm{KMnO} 4} \div 2 \mathrm{~V}_{\mathrm{H} 2 \mathrm{O} 2}
$$

where $\mathrm{C}_{\mathrm{H} 2 \mathrm{O} 2}$ is the $\mathrm{H}_{2} \mathrm{O}_{2}$ concentration $\left(\mathrm{mol} \mathrm{L}^{-1}\right), \mathrm{C}_{\mathrm{KMnO} 4}$ is the precise concentration of $\mathrm{KMnO}_{4}$ solution $\left(\mathrm{mol} \mathrm{L}^{-1}\right), \mathrm{V}_{\mathrm{KMnO}}$ is the volume of $\mathrm{KMnO}_{4}$ solution consumed during titration $(\mathrm{mL}), \mathrm{V}_{\mathrm{H} 2 \mathrm{O} 2}$ is the volume of $\mathrm{H}_{2} \mathrm{O}_{2}$ solution.

\section{Data availability}

The data that support the plots within this paper and other findings of this study are available from the corresponding author upon reasonable request.

Received: 6 December 2019; Accepted: 17 July 2020;

Published online: 21 August 2020

\section{References}

1. Brillas, E., Sirés, I. \& Oturan, M. A. Electro-fenton process and related electrochemical technologies based on fenton's reaction chemistry. Chem. Rev. 109, 6570-6631 (2009).

2. Puértolas, B., Hill, A. K., García, T., Solsona, B. \& Torrente-Murciano, L. Insitu synthesis of hydrogen peroxide in tandem with selective oxidation reactions: a mini-review. Catal. Today 248, 115-127 (2015).

3. Agarwal, N. et al. Aqueous Au-Pd colloids catalyze selective $\mathrm{CH}_{4}$ oxidation to $\mathrm{CH}_{3} \mathrm{OH}$ with $\mathrm{O}_{2}$ undermild conditions. Science 358, 223-227 (2017).

4. Seh, Z. W. et al. Combining theory and experiment in electrocatalysis: insights into materials design. Science 355, eaad4998 (2017).

5. Fukuzumi, S., Lee, Y. M. \& Nam, W. Solar-driven production of hydrogen peroxide from water and dioxygen. Chem. A Eur. J. 24, 5016-5031 (2018).

6. Imarc group, "Hydrogen Peroxide Market Trends, Share, Growth and Forecast 2018-2023". https://www.imarcgroup.com/hydrogen-peroxidetechnical-material-market-report (2019).

7. Yang, S. et al. Toward the decentralized electrochemical production of $\mathrm{H}_{2} \mathrm{O}_{2}$ : a focus on the catalysis. ACS Catal. 8, 4064-4081 (2018).

8. Berl, E. A new cathodic process for the production of $\mathrm{H}_{2} \mathrm{O}_{2}$. J. Electrochem. Soc. 76, 359-369 (1939).

9. Zheng, Z., Ng, Y. H., Wang, D. W. \& Amal, R. Epitaxial growth of Au-Pt-Ni nanorods for direct high selectivity $\mathrm{H}_{2} \mathrm{O}_{2}$ production. Adv. Mater. 28, 9949-9955 (2016)

10. Chen, Z. et al. Development of a reactor with carbon catalysts for modularscale, low-cost electrochemical generation of $\mathrm{H}_{2} \mathrm{O}_{2}$. React. Chem. Eng. 2 239-245 (2017).

11. Jiang, $\mathrm{Y}$. et al. Selective electrochemical $\mathrm{H}_{2} \mathrm{O}_{2}$ production through twoelectron oxygen electrochemistry. Adv. Energy Mater. 8, 1801909 (2018).

12. Melchionna, M., Fornasiero, P. \& Prato, M. The rise of hydrogen peroxide as the main product by metal-free catalysis in oxygen reductions. Adv. Mater. 31, 1802920 (2018).

13. $\mathrm{Lu}, \mathrm{Z}$. et al. High-efficiency oxygen reduction to hydrogen peroxide catalysed by oxidized carbon materials. Nat. Catal. 1, 156-162 (2018).

14. Kim, H. W., Ross, M. B., Kornienko, N., Zhang, L. \& Guo, J. Efficient hydrogen peroxide generation using reduced graphene oxide based oxygen reduction electrocatalysts. Nat. Catal. 1, 282-290 (2018).

15. Chen, S. et al. Designing boron nitride islands in carbon materials for efficient electrochemical synthesis of hydrogen peroxide. J. Am. Chem. Soc. 140, 7851-7859 (2018)

16. Han, L. et al. In-plane carbon lattice-defect regulating electrochemical oxygen reduction to hydrogen peroxide production over nitrogen-doped graphene. ACS Catal. 9, 1283-1288 (2019).

17. Sa, Y. J., Kim, J. H. \& Joo, S. H. Active edge-site-rich carbon nanocatalysts with enhanced electron transfer for efficient electrochemical hydrogen peroxide production. Angew. Chem. Int. Ed. 58, 1100-1105 (2019). 
18. Campos-Martin, J. M., Blanco-Brieva, G. \& Fierro, J. L. G. Hydrogen peroxide synthesis: an outlook beyond the anthraquinone process. Angew. Chem. Int. Ed. 45, 6962-6984 (2006).

19. Hess, W. T. "Hydrogen Peroxide" in Kirk-Othmer Encyclopedia of Chemical Technology. ed. 4, Vol. 13, 961-995 (Wiley, New York, 1995). .

20. Ayers, K. E., Dalton, L. T. \& Anderson, E. B. Efficient generation of high energy density fuel from water. ECS Trans. 41, 27-38 (2012).

21. Sheng, W., Gasteiger, H. A. \& Shao-Horn, Y. Hydrogen oxidation and evolution reaction kinetics on platinum: acid vs alkaline electrolytes. J. Electrochem. Soc. 157, B1529 (2010).

22. Siahrostami, S. et al. Enabling direct $\mathrm{H}_{2} \mathrm{O}_{2}$ production through rational electrocatalyst design. Nat. Mater. 12, 1137-1143 (2013).

23. Verdaguer-Casadevall, A. et al. Trends in the electrochemical synthesis of $\mathrm{H}_{2} \mathrm{O}_{2}$ : enhancing activity and selectivity by electrocatalytic site engineering. Nano Lett. 14, 1603-1608 (2014).

24. Fellinger, T. P., Hasché, F., Strasser, P. \& Antonietti, M. Mesoporous nitrogendoped carbon for the electrocatalytic synthesis of hydrogen peroxide. J. Am. Chem. Soc. 134, 4072-4075 (2012).

25. Liu, Y., Quan, X., Fan, X., Wang, H. \& Chen, S. High-yield electrosynthesis of hydrogen peroxide from oxygen reduction by hierarchically porous carbon. Angew. Chem. Int. Ed. 54, 6837-6841 (2015).

26. Iglesias, $\mathrm{D}$. et al. $\mathrm{N}$-doped graphitized carbon nanohorns as a forefront electrocatalyst in highly selective $\mathrm{O}_{2}$ reduction to $\mathrm{H}_{2} \mathrm{O}_{2}$. Chem 4, 106-123 (2018).

27. Sun, Y. et al. Efficient electrochemical hydrogen peroxide production from molecular oxygen on nitrogen-doped mesoporous carbon catalysts. ACS Catal. 8, 2844-2856 (2018).

28. Gouérec, P. \& Savy, M. Oxygen reduction electrocatalysis: ageing of pyrolyzed cobalt macrocycles dispersed on an active carbon. Electrochim. Acta $\mathbf{4 4}$ 2653-2661 (1999).

29. Mase, K., Ohkubo, K. \& Fukuzumi, S. Efficient two-electron reduction of dioxygen to hydrogen peroxide with one-electron reductants with a small overpotential catalyzed by a cobalt chlorin complex. J. Am. Chem. Soc. 135 2800-2808 (2013).

30. He, Y. et al. Highly active atomically dispersed $\mathrm{CoN}_{4}$ fuel cell cathode catalysts derived from surfactant-assisted MOFs: carbon-shell confinement strategy. Energy Environ. Sci. 12, 250-260 (2019).

31. Wu, G., More, K. L., Johnston, C. M. \& Zelenay, P. High-performance electrocatalysts for oxygen reduction derived from polyaniline, iron, and cobalt. Science 332, 443-447 (2011).

32. Wang, X. X. et al. Nitrogen-coordinated single cobalt atom catalysts for oxygen reduction in proton exchange membrane fuel cells. Adv. Mater. 30, 1706758 (2018).

33. Yin, $\mathrm{P}$. et al. Single cobalt atoms with precise $\mathrm{N}$-coordination as superior oxygen reduction reaction. Catalysts. Angew. Chem. Int. Ed. 55, 10800-10805 (2016).

34. Zhang, L. et al. Coordination of atomic Co-Pt coupling species at carbon defects as active sites for oxygen reduction reaction. J. Am. Chem. Soc. 140, 10757-10763 (2018).

35. Gong, W. et al. Nitrogen-doped carbon nanotube confined Co- $\mathrm{N}_{\mathrm{x}}$ sites for selective hydrogenation of biomass-derived compounds. Adv. Mater. 31, 1808341 (2019).

36. Sun, X. et al. Single cobalt sites in mesoporous N-doped carbon matrix for selective catalytic hydrogenation of nitroarenes. J. Catal. 357, 20-28 (2018).

37. Sun, Y. et al. Activity-selectivity trends in the electrochemical production of hydrogen peroxide over single-site metal-nitrogen-carbon catalysts. J. Am. Chem. Soc. 141, 12372-12381 (2019).

38. Figueiredo, J. L., Pereira, M. F. R. \& Freitas, M. M. A. Modification of the surface chemistry of activated carbons. Carbon 37, 1379-1389 (1999).

39. Lee, S. W. et al. High-power lithium batteries from functionalized carbonnanotube electrodes. Nat. Nanotechnol. 5, 531-537 (2010).

40. Guo, H., Wang, X., Qian, Q., Wang, F. \& Xia, X. A green approach to the synthesis of graphene nanosheets. ACS Nano 3, 2653-2659 (2009).

41. Yoon, C. M. et al. Electrochemical surface oxidation of carbon nanofibers. Carbon 49, 96-105 (2011).

42. Acik, M. et al. Unusual infrared-absorption mechanism in thermally reduced graphene oxide. Nat. Mater. 9, 840-845 (2010).

43. Acik, M. et al. The role of oxygen during thermal reduction of graphene oxide studied by infrared absorption spectroscopy. J. Phys. Chem. C 115, 19761-19781 (2011)

44. Guo, D. et al. Active sites of nitrogen-doped carbon materials for oxygen reduction reaction clarified using model catalysts. Science 351, 361-365 (2016).

45. Chong, L. et al. Ultralow-loading platinum-cobalt fuel cell catalysts derived from imidazolate frameworks. Science 362, 1276-1281 (2018).

46. Choi, C. H. et al. Achilles' heel of iron-based catalysts during oxygen reduction in acidic medium. Energy Environ. Sci. 11, 3176-3182 (2018).

47. D'Angelo, D. et al. Oxygen functionalities evolution in thermally treated graphene oxide featured by EELS and DFT calculations. J. Phys. Chem. C 121, 5408-5414 (2017).
48. Kortright, J. B., Sun, J., Spencer, R. K., Jiang, X. \& Zuckermann, R. N. Oxygen $\mathrm{K}$-edge scattering from bulk comb diblock copolymer reveals extended, ordered backbones above lamellar order disorder transition. J. Phys. Chem. B 121, 298-305 (2017).

49. Ganguly, A., Sharma, S., Papakonstantinou, P. \& Hamilton, J. Probing the thermal deoxygenation of graphene oxide using high-resolution in situ X-raybased spectroscopies. J. Phys. Chem. C 115, 17009-17019 (2011)

50. Miedema, P. S. et al. Oxygen binding to cobalt and iron phthalocyanines as determined from in situ X-ray absorption spectroscopy. J. Phys. Chem. C 115 25422-25428 (2011)

51. Henkelman, G., Arnaldsson, A. \& Jónsson, H. A fast and robust algorithm for Bader decomposition of charge density. Comput. Mater. Sci. 36, 354-360 (2006).

52. Yang, D., Guo, G., Hu, J., Wang, C. \& Jiang, D. Hydrothermal treatment to prepare hydroxyl group modified multi-walled carbon nanotubes. J. Mater. Chem. 18, 350-354 (2008).

53. Suk, M., Chung, M. W., Han, M. H., Oh, H.-S. \& Choi, C. H. Selective $\mathrm{H}_{2} \mathrm{O}_{2}$ production on surface-oxidized metal-nitrogen-carbon electrocatalysts. Catal. Today 5, 1-7 (2019).

54. Perry, S. C. et al. Electrochemical synthesis of hydrogen peroxide from water and oxygen. Nat. Rev. Chem. 3, 442-458 (2019).

55. Xia, C., Xia, Y., Zhu, P., Fan, L. \& Wang, H. Direct electrosynthesis of pure aqueous $\mathrm{H}_{2} \mathrm{O}_{2}$ solutions up to $20 \%$ by weight using a solid electrolyte. Science 366, 226-231 (2019).

56. Daiyan, R. et al. Electroreduction of $\mathrm{CO}_{2}$ to $\mathrm{CO}$ on a mesoporous carbon catalyst with progressively removed nitrogen moieties. ACS Energy Lett. 3, 2292-2298 (2018)

57. Ravel, B. \& Newville, M. ATHENA, ARTEMIS, HEPHAESTUS: data analysis for X-ray absorption spectroscopy using IFEFFIT. J. Synchrotron Radiat. 12, 537-541 (2005)

58. Jain, A. et al. Commentary: The Materials Project: a materials genome approach to accelerating materials innovation. APL Mater. 1, 011002 (2013).

59. Kresse, G., Furthmüller, J. \& Hafner, J. Ab initio molecular-dynamics simulation of the liquid-metal-amorphous-semiconductor transition in germanium. Phys. Rev. B 49, 1452 (1996).

60. Kresse, G. \& Joubert, D. From ultrasoft pseudopotentials to the projector augmented-wave method. Phys. Rev. B 59, 1758-1775 (1999).

61. Kresse, G. \& Furthmüller, J. Efficient iterative schemes for ab initio totalenergy calculations using a plane-wave basis set. Phys. Rev. B - Condens. Matter Mater. Phys. 54, 11169-11186 (1996).

62. Perdew, J. P., Burke, K. \& Ernzerhof, M. Generalized gradient approximation made simple. Phys. Rev. Lett. 77, 3865-3868 (1996).

63. Grimme, S., Antony, J., Ehrlich, S. \& Krieg, H. A consistent and accurate ab initio parametrization of density functional dispersion correction (DFT-D) for the 94 elements H-Pu. J. Chem. Phys. 132, 154104 (2010).

\section{Acknowledgements}

We thank UNSW Mark Wainwright Analytical Center for providing access to the SEM, TEM, FTIR, XPS and other facilities. We thank Dr Bin Gong from MWAC for the XPS measurements. We also thank Dr David Mitchell from University of Wollongong Electron Microscopy Centre for his assistance in HAADF-STEM measurements. XAS experiments were performed at the 10-ID-B beamline of the Advanced Photon Source, a U.S. Department of Energy (DOE) Office of Science User Facility operated for the DOE Office of Science by Argonne National Laboratory under Contract No. DE-AC0206CH11357. This research used the SXR beamline of the Australian Synchrotron, part of the Australian Nuclear Science and Technology Organization and funded by the Australian Government. The work was supported by the Australian Research Council (ARC) under the Laurate Fellowship Scheme FL-140100081, Discovery Early Career Researcher Award DE170100375 and Linkage Projects funding scheme LP170100691. This research was also undertaken with the assistance of resources provided by the National Computational Infrastructure (NCI) facility at the Australian National University; allocated through both the National Computational Merit Allocation Scheme supported by the Australian Government and the Australian Research Council grant LE190100021 (Sustaining and strengthening meritbased access to the NCI National Facility, 2019-2021). We gratefully acknowledge the support from the Tianjushi Engineering Technology Group. We further acknowledge traveling funding from the Australian Synchrotron Access Program as well. Q.Z. also acknowledges the financial support from the Chinese Scholarship Council and University of New South Wales.

\section{Author contributions}

R.A. and X.L. directed the project. X.L. conceived the concept. R.A. X.L., and Q.Z. designed the experiments. Q.Z. carried out the experiments. N.M.B. and L.T. performed the XAS experiments and analysis the data. X.T. and S.S. performed computational modeling. R.A., X.L., Q.Z., and Z.H. analysed the data. R.A., X.L., Q.Z., and X.T. co-wrote the manuscript.

\section{Competing interests}

The authors declare no competing interests. 


\section{Additional information}

Supplementary information is available for this paper at https://doi.org/10.1038/s41467020-17782-5

Correspondence and requests for materials should be addressed to R.A. or X.L.

Peer review information Nature Communications thanks Chang Hyuck Choi and other, anonymous, reviewers for their contributions to the peer review of this work. Peer review reports are available.

Reprints and permission information is available at http://www.nature.com/reprints

Publisher's note Springer Nature remains neutral with regard to jurisdictional claims in published maps and institutional affiliations. (c) (i) Open Access This article is licensed under a Creative Commons Attribution 4.0 International License, which permits use, sharing, adaptation, distribution and reproduction in any medium or format, as long as you give appropriate credit to the original author(s) and the source, provide a link to the Creative Commons license, and indicate if changes were made. The images or other third party material in this article are included in the article's Creative Commons license, unless indicated otherwise in a credit line to the material. If material is not included in the article's Creative Commons license and your intended use is not permitted by statutory regulation or exceeds the permitted use, you will need to obtain permission directly from the copyright holder. To view a copy of this license, visit http://creativecommons.org/ licenses/by/4.0/.

(C) The Author(s) 2020 